\title{
PROSPECÇÃO DE COMPOSTOS BIOATIVOS DE PLANTAS DA MATA ATLÂNTICA COM POTENCIAL PARA APLICAÇÃO NO TRATAMENTO DAS LEISHMANIOSES
}

\author{
AUTOR: VICTOR NEVES DOS SANTOS \\ CO-AUTOR: GISELE LOPES DE OLIVEIRA \\ CO-AUTOR: SEBASTIAO RODRIGO FERREIRA
}

\begin{abstract}
Resumo: As leishmanioses são zoonoses causadas por mais de 20 espécies de protozoários e apresenta, resumidamente, três formas clínicas, cutânea, mucocutânea e visceral. No Brasil, as leishmanioses ocorrem, principalmente, nas regiões Norte e Nordeste com representatividade de $72 \%$ do total de casos registrado no país. $\mathrm{O}$ tratamento desta parasitose é realizado com antimoniais pentavalentes $(\mathrm{Sb})$ e Anfotericina $\mathrm{B}$, medicamentos não totalmente eficazes, com elevada toxicidade e muitos efeitos colaterais. Com base nisso, o presente trabalho buscou identificar os compostos de origem natural com possível atividade leishmanicida e para tanto foi utilizado a espécie Piper macedoi da família Piperaceae. O óleo essencial foi extraído de folhas frescas por hidrodestilação. Já os extratos orgânicos foram obtidos de folhas secas e moídas, que foram submetidas a extrações com solventes orgânicos. Os extratos obtidos foram testados sobre amastigotas de Leishmania infantum. Todos os extratos obtidos apresentaram atividade sobre o protozoário, sendo que os mais promissores foram o óleo essencial (IC50:222,4 $\mathrm{gg} / \mathrm{mL}$ ) e extrato hexânico (IC50: $171,1 \mu \mathrm{g} / \mathrm{mL}$ ), que demonstraram boa atividade e menor citotoxicidade. Embora os resultados aqui apresentados, ainda sejam preliminares, eles demonstram potencial biotecnológico para o futuro tratamento das leishmanioses.
\end{abstract}

Palavras-chave: Leishmania, bioprospecção, Piper macedoi. 